
Pathophysiology of Haemostasis and Thrombosis

\title{
High Cost Patients and the Consortium Approach
}

\author{
Susan Schonfielda Keith Reid ${ }^{b}$ \\ a Merton, Sutton \& Wandsworth Health Authority, Mitcham, and bNHS Executive, London Regional Office, UK
}

\section{Key Words}

High cost patients - Commissioning consortium • Audit . Haemophilia A - Treatment

\begin{abstract}
The Pan-Thames Haemophilia Consortium was established to provide coherent regional planning of haemophilia services. The Expert Advisory Group is a clinical reference point for the consortium and was established to consider specifically elective high cost treatment programmes. An audit of the first year of consortium activity demonstrated that patients receiving high cost therapy represented $1.6 \%$ of the patient population and received $16 \%$ of the entire treatment budget. The Pan-Thames Consortium provides focused commissioning expertise and a model for national commissioning of haemophilia services.
\end{abstract}

Copyright $\odot 2002$ S. Karger AG, Basel

\section{Introduction}

Specialized services are defined as high-cost, low volume services, needing at least one million population for an adequate burden of disease. In 1997 the new Labour government of the United Kingdom acknowledged that commissioning of specialized services had failed to work in the internal market environment of the National
Health Service [1]. The White Paper quoted a report by the Audit Commission, which concluded that delivery of specialized services had been fragmented during the internal market, and now required stable and coherent regional planning with particular regard to organization and investment [2]. HSC (health service circular) 1998/198 [3] gave effect to this policy and recommended the formation of regional specialist commissioning groups (RSCGs) who would oversee the arrangements for planning, procuring and managing these services.

\section{The Pan-Thames Haemophilia Consortium}

This is one of the first consortia set up by the London RSCG and was formed in April 2000. The Pan-Thames Haemophilia Consortium commissions services from haemophilia Comprehensive Care Centres (CCCs) serving London and the surrounding regions of Kent, Surrey, Sussex, Hertfordshire and Essex. This area includes 24 health authorities, and covers a population of 13 million inhabitants. The Consortium aims to provide a coordinated and strategic approach to the commissioning of haemophilia services through planning of a service model, procurement of an agreed service specification and performance monitoring. It is led by Croydon Health Authority and comprises four sub-groups: strategy, finance, information and clinical. It is the work of the clinical subgroup that will be described in this paper.

\section{KARGER \\ Fax + 41613061234 \\ E-Mail karger@karger.ch \\ www.karger.com

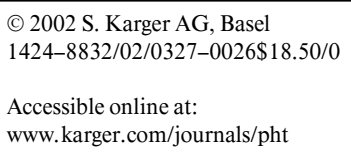

Dr. Susan Schonfield

Merton, Sutton \& Wandsworth Health Authority, The Wilson, Cranmer Road 6

Mitcham, Surrey CR4 4TP (UK)

Tel. +44208687 4801, Fax +442086874536

E-Mail susan.schonfield@mswha.sthames.nhs.uk 


\section{The Clinical Expert Advisory Group (EAG)}

This group was formed to provide expert advice on the very high cost treatment programmes required by haemophilia patients who have acquired neutralising allo-antibodies (inhibitors) to coagulation factors. These treatments may relate to elective procedures such as operations or to immune tolerance induction. High cost was defined as those treatments with a concentrate purchase value of at least $£ 100,000$ in a three-month period.

Membership of the EAG comprises clinicians from four London CCCs, two public health specialists (one a former haematology consultant), two patient representatives, one haemophilia specialist nurse (from outside the Thames region) and one commissioning manager.

Initial tasks for the EAG involved establishing terms of reference and developing referral guidelines, including a patient information leaflet and consent form. The group only considers proposals for elective treatment and all patient referrals are presented anonymously. The clinical advice agreed on is communicated to the patient's health authority, with the letter copied to the clinician and, if requested, to the patient. The health authority then decides whether it wishes to accept the group's advice.

\section{Clinical A udit}

An audit of high cost patients treated in the first year of the Consortium (2000-2001) has recently been completed [4]. The audit objective was to identify the features of treatment programmes leading to high costs and to inform decisions on the purchase of haemophilia services. The study population included all patients with haemostatic disorders who received coagulation factor concentrate under the guidance of CCCs within the Haemophilia Consortium. The patients were categorised according to the cost of their coagulation factor concentrate use during the year. Specific clinical indications for individual high cost patients were then clarified through communication with the respective haemophilia treatment centres.

During the audit period, approximately 900 patients received coagulation concentrate treatment with a total cost of $£ 38$ million. For 96 of the 900 patients, treatment costs were in excess of $£ 100,000$ over the 12 -month period. Fourteen patients (1.6\%) satisfied the criteria of a high-cost patient, each receiving concentrate valued in excess of $£ 100,000$ over a 3-month period. The cost of their treatment accounted for $16 \%(£ 6,167,000)$ of the total concentrate budget. Of the 13 evaluable high-cost patients, 10 had severe haemophilia A (factor VIII less than $1 \mathrm{IU} / \mathrm{dl}$ ), 1 had moderate haemophilia A (factor VIII 2-5 IU/dl) and 2 had mild haemophilia A (factor VIII greater than $5 \mathrm{IU} / \mathrm{dl}$ ). Two patients were sero-positive for the HIV virus, one of which was co-infected with the hepatitis $\mathrm{C}$ virus. Four patients were sero-negative for the HIV virus but sero-positive for the hepatitis $C$ virus. Nine of the 13 patients had inhibitory antibodies to factor VIII.

The treatment regimes of these 13 high-cost patients were listed as follows: 4 patients without factor VIII inhibitors were receiving regularly scheduled factor VIII concentrate in a prophylactic manner; 3 inhibitor patients were undergoing immune tolerance induction programmes with the aim of eradicating their inhibitory antibody; 4 patients were receiving inhibitor bypassing agents as required in response to bleeding episodes; and 2 patients received inhibitor bypassing agents for specific clinical problems, in one patient for the management of an infected joint prosthesis and in the other treatment for fulminant hepatic failure following an episode of variceal bleeding.

Two of the 4 patients receiving prophylactic factor VIII concentrate were teenagers of higher than average body weight, who had not yet undergone bone fusion of epiphyseal growth plates. They were receiving appropriate doses of recombinant factor VIII concentrate. One adult was receiving prophylaxis with plasma derived factor VIII concentrate, the clinical indications for which were not clear. Two of the 3 patients on immune tolerance induction programmes were children. One had successfully achieved full immune tolerance following initial central line insertion under recombinant factor VIIa cover. The other had achieved only partial success at immune tolerance induction following both high and intermediate dose regimes and continued on three times per week factor VIII concentrate therapy as a low dose immune tolerance induction regime, with recombinant factor VIIa as required for acute bleeding episodes. The third patient was an adult whose immune tolerance programme had failed and been discontinued, with reversion to a plasma derived inhibitor bypassing agent as required to treat bleeding episodes.

\section{Discussion}

The treatment categories for high cost patients included both the management of bleeding episodes and acute surgery for patients with specific coagulation factor 
inhibitors, immune tolerance induction programmes for patients with inhibitors, and appropriate prophylactic factor VIII replacement programmes for young adults of large body weight. Six of the 13 high cost treatment episodes were considered emergencies and the remaining seven were elective treatments. Two of these cases had been referred to the EAG for consideration. It should be noted that the EAG had started to receive referrals towards the end of the financial year covered by the retrospective audit.

The clinical advisory role of the EAG is still developing and several questions arise in terms of risk-sharing. These include under what circumstances would a health authority refuse to accept the clinical advice of the EAG, and whether all patients identified through financial returns to the consortium who meet the high cost criteria should be referred to the EAG. The audit shows that not all elective high cost cases were automatically referred to the group for consideration. A more consistent practice in referral of high cost treatment programmes for EAG con- sideration will be facilitated by improved data collection and outcome monitoring for this high cost but low volume caseload.

\section{Declaration of Interests}

Dr. Susan Schonfield's attendance at the Evidence Based Haemostasis seminar was funded by Croydon Health Authority and her speaker's honorarium will be paid to Croydon Health Authority. Dr. Keith Reid's attendance was funded by the London Region Public Health Training Programme.

References

1 'The New NHS - Modern, Dependable'. Department of Health, London, 1997, § 7.23.

2 'Higher Purchase: Commissioning Specialist Services in the NHS'. Audit Commission, London 1997.

3 HSC (health service circular) 1998/198. Department of Health, London, 1998.

4 Reid K, Schonfield S: Review of haemophilia patients deemed 'high-cost' conducted for the Pan Thames Haemophilia Consortium. Seville WFH, May 2002, poster in preparation. 